\title{
Penggunaan Aplikasi Zoom Cloud Meeting pada Mata Kuliah Mekanika dan Termostatistika saat Pandemi COVID-19
}

\author{
${ }^{1}$ Dedi Riyan Rizaldi, ${ }^{1}$ Ziadatul Fatimah \\ ${ }^{1}$ Magister Pendidikan IPA, Universitas Mataram, Jln. Pendidikan No. 37 Mataram, Nusa \\ Tenggara Barat 83125 \\ Email Korespondensi:dedi0313@gmail.com,ziadatulfatimah96@gmail.com
}

\begin{tabular}{|c|c|}
\hline$A r$ & $t$ \\
\hline $\begin{array}{l}\text { Article History } \\
\text { Received: June } 2020 \\
\text { Revised: December } 2020 \\
\text { Published: December } 2020\end{array}$ & \multirow{2}{*}{$\begin{array}{l}\text { The purpose of writing this article is to explain the application of online based } \\
\text { learning using the Zoom Cloud Mettng application during the COVID-19 } \\
\text { pandemic. The writing of this article uses a qualitative method of literature } \\
\text { review by collecting data in the form of secondary data obtained from various } \\
\text { sources such as articles, notes, or other scientific sources. The data collected is } \\
\text { then analyzed inductively. Based on the literature review, data analysis, and } \\
\text { discussion, it can be concluded that the Zoom Cloud Metting application is an } \\
\text { effective medium used in the learning process during the COVID-19 pandemic } \\
\text { because it is able to facilitate educators and learning to be able to interact } \\
\text { while continuing to prioritize health protocols during the pandemic COVID-19, } \\
\text { namely Physical Distancing or maintaining distance. }\end{array}$} \\
\hline $\begin{array}{l}K \boldsymbol{K e} \\
O r \\
Z c \\
P c\end{array}$ & \\
\hline Int & Abstrak \\
\hline $\begin{array}{l}\text { Seja } \\
\text { Dite } \\
\text { Dire } \\
\text { Dip }\end{array}$ & \multirow{2}{*}{$\begin{array}{l}\text { Tujuan penulisan artikel ini untuk menjelaskan tentang penerapan } \\
\text { pembelajaran berbasis online menggunakan aplikasi Zoom Cloud Mettng pada } \\
\text { masa pandemi COVID-19. Penulisan artikel ini menggunakan metode kualitatif } \\
\text { berupa kajian pustaka dengan mengumpulkan data berupa data sekunder yang } \\
\text { diperoleh dari berbagai sumber seperti artikel, catatan, ataupun sumber ilmiah } \\
\text { lainnya. Data yang dikumpulkan kemudian dianalisis secara induktif. } \\
\text { Berdasarkan hasil tinjauan pustaka, analisis data, dan diskusi dapat disimpulkan } \\
\text { bahwa aplikasi Zoom Cloud Metting merupakan salah satu media yang efektif } \\
\text { digunakan dalam proses pembelajaran selama masa pandemi COVID-19 karena } \\
\text { mampu memfasilitasi pendidik dan pembelajaran untuk dapat berinteraksi } \\
\text { dengan tetap mengedepankan protokol kesehatan selama masa pandemi } \\
\text { COVID-19 yaitu Physical Distancing atau menjaga jarak. }\end{array}$} \\
\hline & \\
\hline
\end{tabular}

Sitasi: Rizaldi, B. R., \& Fatimah, Z. (2020). Panerapan Pembelajaran Berbasis Online Menggunakan Aplikasi Zoom Cloud Meeting Pada Masa Pandemi COVID-19 . Kappa Journal, 4 (1), 225-232

\section{PENDAHULUAN}

Pendidikan memiliki peranan yang sangat penting dalam mempersiapkan sumber daya manusia untuk menghadapi berbagai macam tantangan yang muncul di masa akan datang (Jailani, et. al., 2017). Pendidikan harus mampu memfasilitasi semua pembelajar untuk terus dapat belajar dalam kondisi dan keadaan apapun termasuk pada masa pandemi COVID-19 yang saat ini sedang melanda berbagai dunia termasuk Indonesia. Pandemi ini memberikan dampak yang sangat besar di semua bidang kehidupan. Pendidikan menjadi salah satu fokus penting karena mengharuskan terjadinya penyesuaian agar proses pembelajaran tetap dapat berlangsung.

Pandemi COVID-19 memaksa pemerintah untuk mengeluarkan kebijakan social distancing atau physical distancing untuk meminimalisir atau memutus mata rantai penyebaran COVID-19 di masyarakat. Oleh karena hal tersebut memberikan dampak dalam 
proses perkuliahan yang tidak lagi dilakukan dengan tatap muka dalam satu ruangan yang sama. Menindaklanjuti kebijakan tersebut maka berbagai perguruan tinggi di Indonesia termasuk Universitas Mataram berupaya memfasilitasi pembelajaran dengan menggunakan pembelajaran berbasis online.

Sistem pembelajaran online memberikan kesempatan kepada mahasiswa untuk tetap dapat melakukan perkuliahan walaupun tidak berada satu ruangan yang sama dengan pendidik (Anderson dan Elloumi, 2004). Beberapa manfaat pembelajaran berbasis online menurut Alessi dan Trollip (2001) antara lain 1). Mengatasi persoalan jarak jauh, 2). Membangun suasana belajar yang baru, 3). Mendorong sikap belajar aktif, 4). Mengontrol proses belajar, 4). Menumbuhkan sikap kerja sama, dan 5). Mengakomodasi berbagai gaya belajar.

Salah satu aplikasi online yang saat ini sering digunakan dalam membantu proses pembelajaran yaitu menggunakan aplikasi Zoom Cloud Meeting. Penggunakan aplikasi ini pada dasarnya sesuai dengan tuntutan dari dampak revolusi industri 4.0 dengan menekankan pada digitalisasi sistem atau berbasis teknologi (Abidin, et. al., 2020). Dengan situasi pandemi COVID-19 saat ini maka semua civitas pendidikan khususnya pada tingkat perguruan tinggi harus mampu menggunakan berbagai aplikasi online untuk tetap melakukan proses pembelajaran.

Berdasarkan permasalahan di atas perlu adanya fasilitas dalam melaksanakan proses pembelajaran untuk tetap meningkatkan kompetensi mahasiswa selama menerapkan sistem physical distance (jaga jarak) di masa pandemi COVID-19 yang sedang melanda di Indonesia saat ini. Sehingga penerapan pembelajaran online menggunakan aplikasi Zoom Cloud Meeting merupakan salah satu alternatif yang dapat digunakan untuk mengatasi permasalah proses pembelajaran saat ini.

\section{METODE}

Penelitian ini menggunakan metode kualitatif berupa kajian pustaka dengan mengumpulkan data berupa data sekunder yang diperoleh dari berbagai sumber seperti artikel, catatan, ataupun sumber ilmiah lainnya (Rizaldi, et. al. 2020). Menurut Zed (2014) menggambarkan bahwa kegiatan kajian pustaka tidak hanya sebatas mempersiapkan kerangka penelitian tetapi juga memperoleh berbagai data penelitian.

Data yang dikumpulkan kemudian dianalisis secara induktif untuk menghasilkan grounded theory, yaitu teori yang muncul dari data bukan dari hipotesis (Setyosari, 2013). Langkah-langkah dalam penulisan artikel ini antara lain 1) Mengidentifikasi permasalah yang akan menjadi bahan kajian, 2) menentukan metode untuk mengumpulkan data, 3) melakukan kajian pustaka dari berbagai sumber, 5) memilih prosedur analisis data, dan 6) menarik kesimpulan (Danim, 2003).

\section{HASIL DAN PEMBAHASAN}

\section{Paradigma Pembelajaran di Masa Pandemi COVID-19}

Indonesia merupakah salah satu negara yang terkena dampak dari adanya pandemi COVID-19. Pandemi merupakan suatu kondisi dimana penyakit dapat dengan mudah tertular ke orang lain karena kondisi tertentu (Rusdiana, et. al. 2020). Menurut Gugus Tugas Percepatan Penanganan COVID-19 (2020), bahwa sampai 21 Mei 2020 sudah terdapat 20.162 orang dinyatakan positif COVID-19. Pandemi ini menyebabkan terjadinya perubahan pola belajar dimana pemerintah pusat hingga daerah telah melakukan kebijakan bahwa semua proses pembelajaran termasuk di perguruan tinggi harus diliburkan dan dilakukan dari rumah. Hal tersebut dilakukan untuk memutus mata rantai penyebaran COVID-19 khususnya saat terjadinya proses pembelajaran yang mempertemukan banyak orang.

Universitas Mataram selaku salah satu perguruan tinggi negeri merespon kebijakan pemerintah dengan mengeluarkan surat edaran No. 3346/UN.18/TU/2020 bahwa kegiatan 
perkuliahan dapat dilakukan melalui sistem online dengan memanfaatkan media pembelajaran seperti Zoom Cloud Meeting, Goggle Classroom, Moodle, WAG, dan lainnya. Berdasarkan himbauan tersebut maka penggunaan aplikasi Zoom Cloud Meeting diharapkan mampu menjadi solusi agar proses pembelajaran pada tingkat perguruan tinggi tetap dapat dilaksanakan.

\section{Pembelajaran Online menggunakan Aplikasi Zoom Cloud Meeting}

Pembelajaran online atau biasa disebut e- learning merupakan pembelajaran yang memanfaatkan jaringan internet untuk memfasilitasi proses pembelajaran jarak jauh sebagai upaya dalam meningkatkan aspek pengetahuan dan keterampilan pembelajaran. Menurut Yazdi (2012) bahwa e-learning adalah pembelajaran yang menggunakan rangkaian elektronik sebagai bentuk interaksi, bimbingan, ataupun menyampaikan isi pembelajaran. Sedangkan menurut Setiawan, et. al. (2019) bahwa e-learning merupakan sistem informasi yang banyak digunakan dengan tujuan memberikan penghematan waktu dan sumber daya dalam pelaksanaan kegiatan akademik.

Pembelajaran online memiliki beberapa kelebihan dibandingkan pembelajaran yang bersifat konvensional antara lain 1). Memungkinkan tercapainya bahan ajar ke pembelajar dengan menggunakan media internet, intranet, ataupun jaringan komputer lainnya, 2). Mampu menciptakan pembelajaran pada berbagai kondisi dan waktu (bersifat fleksibel), dan 3). Pembelajar dapat mempelajari kembali bahan ajar atau materi jika dibutuhkan karena file dapat disimpan baik menggunakan komputer (Zakia, et. al. 2019) (Kratochvil, 2013) (Hartati, et. al. 2019). Selain memiliki kelebihan tentunya terdapat beberapa kekurangan sistem pembelajaran online atau e-learning antara lain 1). Kurang terjadinya interaksi antara pendidik dengan pembelajaran, 2). Membutuhkan koneksi internet untuk dapat terhubung ke dalam proses pembelajaran, 3). Pembelajaran yang memiliki movitasi rendah akan sangat sulit untuk mengikuti proses pembelajaran, dan 4). Membutuhkan keterampilan dalam memanfaatkan teknologi yang sedang berkembang (Yazdi, 2012)(Pratiwi dan Andayono, 2019)(Gunawan, et. al., 2020).

Menurut Setyosari bahwa hal terpenting yang harus diperhatikan dalam proses pembelajaran online meliputi 1). Konteks materi yang disajikan relevan dengan tujuan pembelajaran yang akan dicapai, 2). Diupayakan menampilkan materi dalam bentuk gambar atau grafik agar mudah dipahami, dan 3). Mengembangkan pengetahuan dan keterampilan untuk dijadikan pegangan dalam dunia nyata (dalam Abidin, et. al. 2020). Oleh karena itu aplikasi yang digunakan dalam proses e-learning setidaknya memuat ciri-ciri atau karakteristik yang dijelaskan seperti di atas.

Berbagai aplikasi online saat ini tersedia untuk membantu komunikasi jarak jauh yang memungkinkan setiap orang dapat bertatap muka tanpa harus bertemu secara langsung. Salah satu aplikasi yang saat ini sering digunakan dalam dunian pendidikan khususnya perguruan tinggi dalam melakukan berbagai kegiatan seperti perkuliahan, seminar hasil, ujian skripsi/tesis, serta kegiatan lainnya adalah Zoom Cloud Metting. Aplikasi ini merupakan media komunikasi berbasis video yang dapat digunakan pada berbagai perangkat seluler, komputer, maupun telepon. Tampilan aplikasi Zoom Cloud Metting seperti pada gambar di bawah ini 


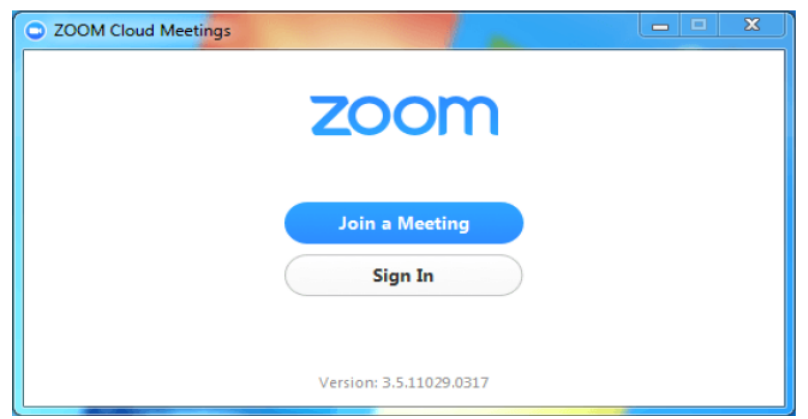

Gambar 1. Tampilan Awal Aplikasi Zoom Cloud Metting

Aplikasi Zoom Cloud Metting dapat didownload pada https://zoom.us/download, playstore, atau appstore. Aplikasi ini dilengkapi beberapa fitur penunjang untuk mempermudah proses komunikasi seperti

1. Memiliki kualitas video dan audio HD.

2. Dapat berbagi layar secara langsung.

3. Dapat berbagi file berupa gambar, audio, ataupun video.

4. Dapat merekam proses yang terjadi selama menggunakan Zoom Cloud Metting.

5. Dapat melakukan obrolan menggunakan teks.

6. Bekerja melalui jaringan Wifi, 4G LTE, dan 3G.

Menurut artikel yang ditulis oleh Brahma, (2020) bahwa aplikasi Zoom Cloud Meeting dapat dijadikan alternatif media pembelajaran online di masa pandemi COVID-19. Dosen dan mahasiswa dapat melakukan video konferensi berupa presentasi dengan berkirim pesan, berbicara, hingga mengirimkan file pembelajaran seperti word, power point, dan bahan ajar lainnya. Selain itu menurut Seran, et. al. (2020) mengatakan bahwa aplikasi video conference seperti Zoom Cloud Meeting dapat dijadikan sebagai media pendukung pembelajaran berbasis Outdoor dalam meningkatkan kemampuan mahasiswa dalam menulis karya ilmiah. Namun terdapat beberapa kekurangan dari aplikasi Zoom Cloud Metting, menurut Gunawan, et. al. (2020) bahwa penggunaan aplikasi ini hanya efektif sekitar 40 menit secara gratis, selebihnya pemilik akun harus menginstal aplikasi yang bersifat premium atau berbayar. Sedangkan menurut Sharma (2020) bahwa tingkat keamaan aplikasi ini masih perlu ditingkatkan agar memastikan data pengguna tidak dapat diretas oleh orang lain.

\section{Penerapan Pembelajaran Online menggunakan Aplikasi Zoom Cloud Meeting di Perguruan Tinggi}

Aplikasi Zoom Cloud Meeting dinilai menpunyai kualitas yang mempenuhi. Dalam tahun ini saja, jumlah pengguna aplikasi ini telah mengalami perkembangan pesat. Diperkirakan hampir semua perguruan tinggi (PT) di Indonesia menggunakan aplikasi Zoom Cloud Meeting dalam proses pembelajaran selama pandemi COVID-19.

Pada Zoom Cloud Meeting interaksi antara dosen dan mahasiswa dapat dilakukan tanpa ada lagi batasan ruangan dan waktu. Dosen dapat memanfaatkan aplikasi ini baik sebagai pengganti ketika dosen harus berhalangan hadir atau sebagai pendukung perkuliahan seperti memberikan materi diawal perkuliahan berkenaan dengan tujuan pembelajaran atau dapat juga memberikan materi sebagai rangkuman, memberikan tugas bahkan tes.

Materi perkuliahan, bahan diskusi atau soal tes dapat diunggah ke dalam sistem Zoom Cloud Meeting, untuk dapat dilihat secara bersama-sama oleh dosen dan mahasiswa. Penyajian materi dalam bentuk file dengan berbagai format seperti PDF, DOC, XLS, PPT dan berbagai bentuk lainnya. Sistem aplikasi yang sederhana dimaksudkan agar lebih mudah dipelajari dan dioperasikan oleh mahasiswa. Komunikasi atau interaksi antara dosen dan mahasiswa didesain seolah mahasiswa berada langsung dihadapan dosen melalui layar komputer atau handphone. Sedapat mungkin komunikasi antara dosen dan mahasiswa dilakukan melalui sistem komunikasi dua arah. Pada komunikasi secara langsung 
(synchronous), yaitu pada saat dosen memberikan materi kuliah, mahasiswa dapat langsung menyaksikan sehingga dosen tidak perlu harus menuliskan.

Aplikasi Zoom Cloud Meeting sangat sesuai untuk kegiatan pembelajaran online, yang mampu mendukung jumlah peserta belajar lebih dari 20 orang, dan fitur conference tool bisa digunakan oleh setiap peserta, tidak hanya host atau admin.Aplikasi ini mendukung antar perangkat seperti laptop atau smartphone. Jika menjadi presenter (sebagai host yang akan mengadakan meeting) maka harus mempunyai account Zoom Cloud Meeting dan bisa memulai menjalakankan aplikasi ini dan jika telah login maka tampilannya akan seperti di bawah ini kemudian memulai dengan memiliih salah satu pilihan yaitu new meeting

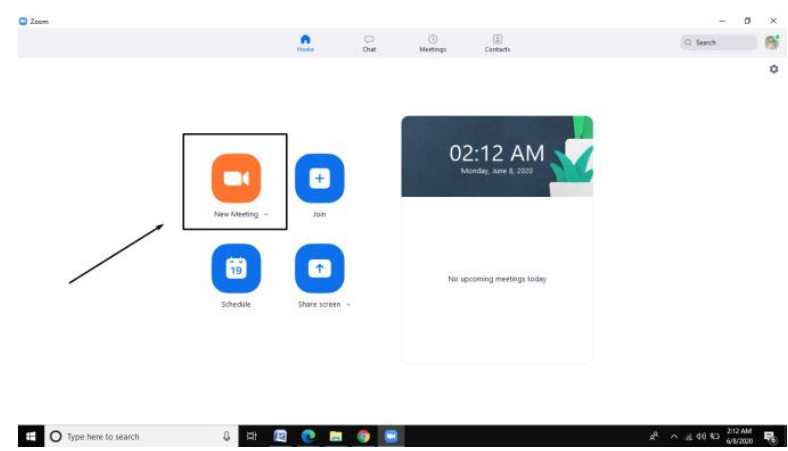

Gambar 2. Tampilan untuk Memulai Metting pada Aplikasi Zoom Cloud Metting

Host harus mengaktifkan webcam di PC/Laptop dan perangkat maupun peserta harus terkoneksi dengan jaringan internet. Jika menggunakan HP/Tablet maka bisa mengaktifkan kamera depan di gadget. Setiap Host yang memulai sesi meeting akan diberikan satu ID unik Zoom Cloud Meeting sehingga peserta lain yang ingin join meeting bisa memasukkang ID tersebut sebagai syarat masuk ke dalam grup yang sudah direncanakan. Cara mengetahui ID Zoom Cloud Meeting adalah dengan melihat nomor unik yang tertera di pojok kiri atas tampilan Zoom.

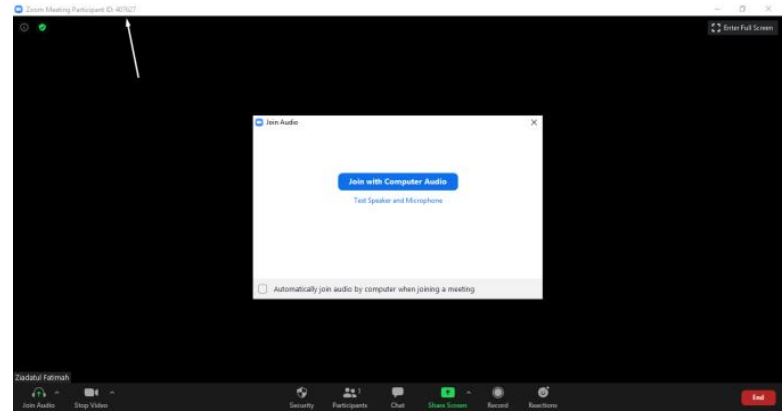

Gambar 3. ID Zoom Cloud Metting

Sebagai peserta juga bisa memilih salah satu pilihan yaitu join, seperti pada gambar di bawah ini

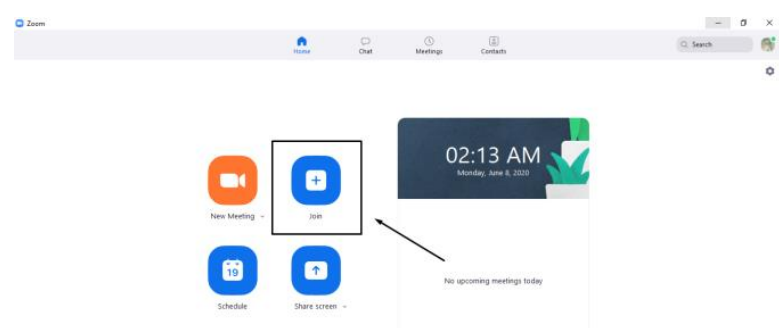

Gambar 4. Tampilan untuk Join Aplikasi Zoom Cloud Metting 
Peserta bisa memasukkan ID dan password yang sudah diberikan oleh host dengan tampilan seperti gambar dibawah ini
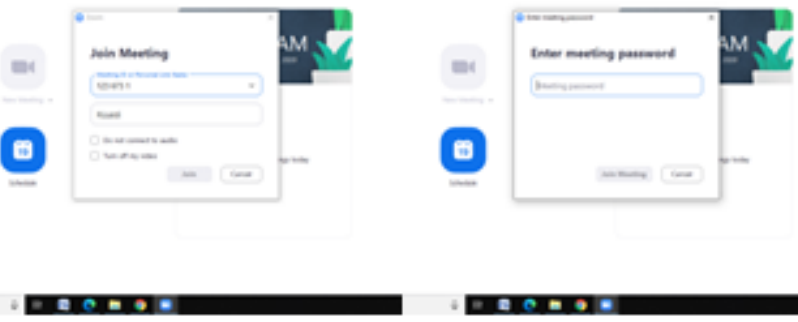

Gambar 5. Masukkan ID dan Password

Setelah host menerima peserta metting, maka tampilan pada layar laptop/ android akan terlihat seperti gambar di bawah ini

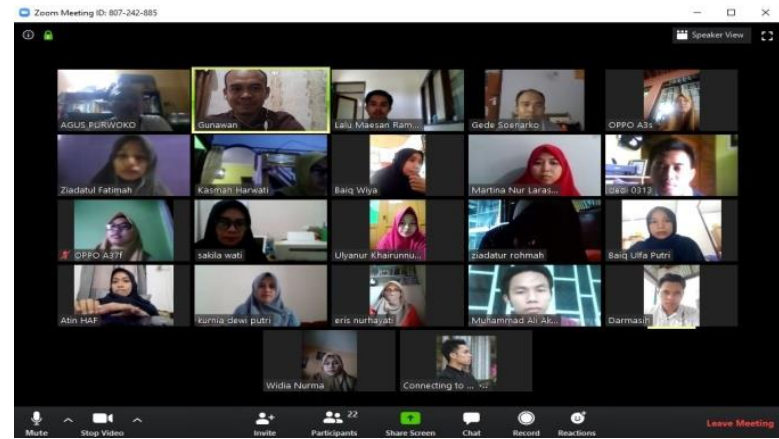

Gambar 6. Masuk ke Room

Host atau peserta yang ingin menampilkan PDF, DOC, XLS, PPT dan berbagai bentuk lainnya ke dalam metting bisa mengklik pilihan pada tampilan Zoom Cloud Meeting yaitu Shareing Screen

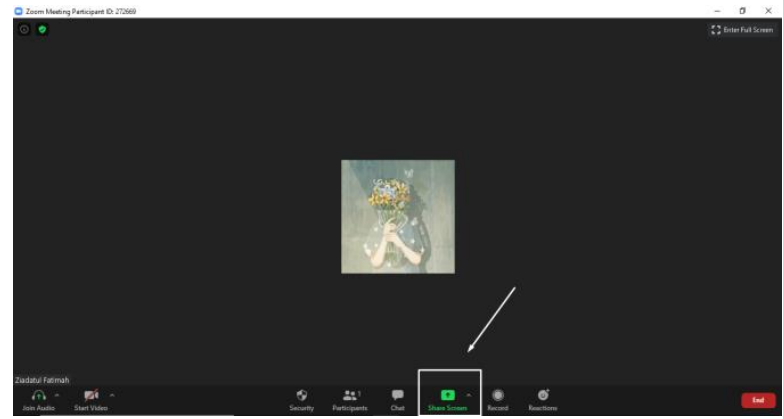

Gambar 7. Untuk Memulai Shareing Screen

Setelah mengklik Shareing Screen, tampilan yang ada pada layar aplikasi ini akan terlihat seperti gambar di bawah ini

\section{DINAMIKA LAGRANGAN DAN HAMILTONAN}

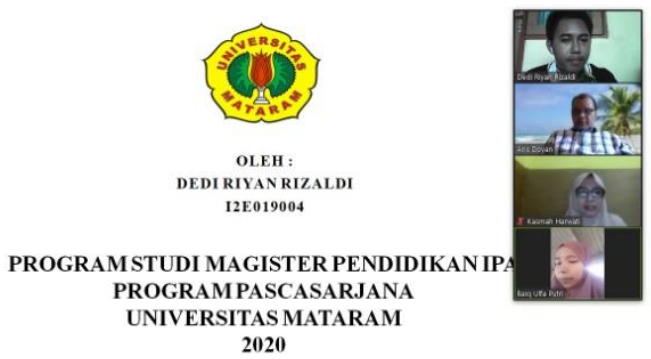

Gambar 8. Presentasi Menggunakan Aplikasi Zoom Cloud Metting 
Kemudian host atau peserta bisa melakukan presentasi dan dapat dilihat oleh seluruh peserta yang ada di dalam aplikasi Zoom Cloud Meeting. Dalam sebuah meeting, banyak peserta yang ingin ikut berbicara dan mengemukakan gagasan. Jika semua ingin berbicara maka suasana meeting akan gaduh dan kacau. Oleh karena itu Zoom Cloud meeting telah menyediakan satu fasilitas khusus yaitu fitur Q\&A yang bisa digunakan peserta untuk berbicara tanpa harus mengangkat tangan dan menunggu host mempersilahkan. Setiap tulisan yang diketik dalam Q\&A di perangkat peserta maka akan masuk ke kolom Chat di samping kanan layar zoom host sehingga host akan dengan mudah melihat chat tersebut untuk kemudian menjawabnya satu persatu. Selain itu chat inipun bukan hanya bisa dilihat oleh host namun juga bisa dilihat di layar peserta meeting lainnya

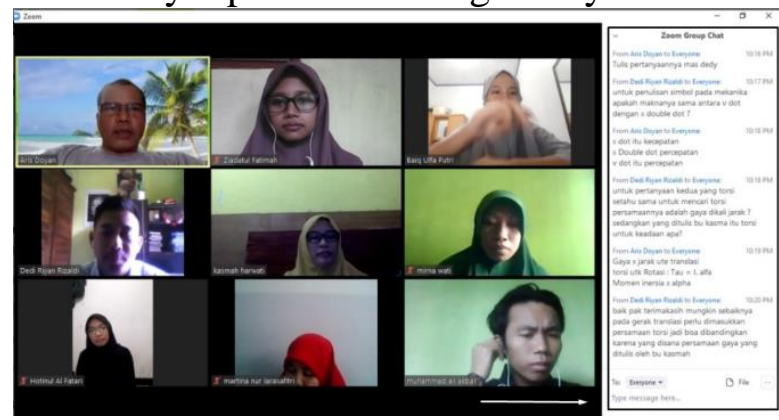

Gambar 11. Q\&A / Chat

\section{KESIMPULAN}

Berdasarkan penjelasan di atas bahwa aplikasi Zoom Cloud Metting merupakan salah satu media yang efektif digunakan dalam proses pembelajaran selama masa pandemi COVID19 karena mampu memfasilitasi pendidik dan pembelajaran untuk dapat berinteraksi dengan tetap mengedepankan protokol kesehatan selama masa pandemi COVID-19 yaitu Physical Distancing atau menjaga jarak.

\section{SARAN}

Saran yang dapat diberikan penulis yaitu semoga kedepannya aplikasi Zoom Cloud Metting tidak hanya diterapkan pada pembelajaran pada tingkat perkuliahan, namun juga dapat diterapkan pada tingkat sekolah dasar dan menengah karena mampu melihat secara langsung keaktifan peserta dalam mengikuti proses pembelajaran.

\section{DAFTAR PUSTAKA}

Abidin, Z., Rumansyah, \& Arizona, K. (2020). Pembelajaran Online berbasis Proyek Salah Satu Solusi Kegiatan Belajar Mengajar di Tengah Pandemi COVID-19. Jurnal Ilmiah Profesi Pendidikan, 5(1): 64-70.

Alessi, S. M. \& Trollip, S. R. (2001). Multimedia for Learning: Method and Development Ed. 3. Massachusetts: Allyn dan Bacon.

Anderson, T. \& Ellouni, F. (2004). Theory and Practice of Online Learning. Athabasca: Athabasca University.

Brahma, I. A. (2020). Penggunaan Zoom sebagai Pembelajaran Berbasis Online dalam Mata Kuliah Sosiologi dan Antropologi pada Mahasiswa PPKN di STKIP Kusumanegara Jakarta. Jurnal Ilmu Pendidikan Nonformal, 6(2): 97-102.

Gugus Tugas Percepatan Penanganan COVID-19. (2020). Data COVID-19 di Indonesia. Dari https://covid19.go.id/ diakses tanggal 22 Mei 2020.

Gunawan, Suranti, N. M. Y., \& Fathoni. Variations of Models and Learning Platforms for Prospective Teachers During the COVID-19 Pandemic Period. Indonesian Journal of Teacher Education, 1(2): 61-70.

Hartati, S., Susilowati, E., \& Misbah. (2019). Media Pembelajaran Fisika SMA Berbasis ELearning di Kabupaten Tanah Laut sebagai Upaya Melatihkan Literasi Digital. 
Prosiding Seminar Nasional Pengabdian kepada Masyarakat Maret 2019 (20-24). Banjarmasin, Indonesia: Universitas Lambung Mangkurat..

Kratochvil, J. 2013. Evaluation of E-learning course, information literacy, for medical students. The Electronic Library. Vol. 31(1): 55-69.

Pratiwi, D. S., \& Totoh Andayono, S. T. (2019). Persepsi Mahasiswa Program Studi Pendidikan Teknik Bangunan Terhadap Penggunaan E-Learning. CIVED, 6(4):1-6.

Setiawan, A., et. al. (2019). Pengembangan E-Learning sebagai Media Pembelajaran Pendidikan Vokasi. Seminar Santika pada 4-5 September (52-56). Surabaya, Indonesia: Program Studi Pendidikan Vokasi: Universitas Negeri Surabaya.

Yazdi, M. (2012). E-Learning Sebagai Media Pembelajaran Interaktif Berbasis Teknologi Informasi. Jurnal Ilmiah Foristek, 2(1): 143-152.

Zakia, A. R., Djamahar, R., \& Rusdi. (2019). Pengaruh Pembelajaran Berbasis Masalah menggunakan Media Sosial E-Learning terhadap Hasil Belajar Siswa Sekolah Menengah pada Sistem Pencernaan. Jurnal Pendidikan Biologi, 4(1): 21-28. 